Article

\title{
Comparison Study on Welding Temperature and Joint Characteristics of AZ31 Magnesium Alloy by Ultrasonic and Heat Pipe Assisted FSW
}

\author{
Cheng-Gang Wei, Sheng Lu *, Liang-Yu Chen (1) and Mao-You Xu
}

Citation: Wei, C.-G.; Lu, S.; Chen, L.-Y.; Xu, M.-Y. Comparison Study on Welding Temperature and Joint Characteristics of AZ31 Magnesium Alloy by Ultrasonic and Heat Pipe Assisted FSW. Metals 2022, 12, 267. https://doi.org/10.3390/ met12020267

Academic Editor: Pierpaolo Carlone

Received: 28 November 2021

Accepted: 18 January 2022

Published: 31 January 2022

Publisher's Note: MDPI stays neutral with regard to jurisdictional claims in published maps and institutional affiliations.

Copyright: (C) 2022 by the authors. Licensee MDPI, Basel, Switzerland. This article is an open access article distributed under the terms and conditions of the Creative Commons Attribution (CC BY) license (https:// creativecommons.org/licenses/by/ $4.0 /)$.
School of Materials Science and Engineering, Jiangsu University of Science and Technology, Zhenjiang 212003, China; 181060001@stu.just.edu.cn (C.-G.W.); lychen@just.edu.cn (L.-Y.C.); 192060016@stu.just.edu.cn (M.-Y.X.)

* Correspondence: lusheng_ktz@just.edu.cn

\begin{abstract}
As an important factor in friction stir welding (FSW) process, temperature directly affects the microstructures and mechanical properties of welded joints. The present work aims to investigate the welding temperature and joint characteristics of AZ31 magnesium alloy under three FSW conditions: conventional friction stir welding (FSW), ultrasonic assisted friction stir welding (UaFSW), and ultrasonic and heat pipe assisted friction stir welding (UHaFSW), respectively. The results show that the welding temperature distributions and the characteristic of "non-uniformity" are presented in the FSW and UaFSW joints along the welding and horizontal directions. Compared with conventional FSW, UaFSW can effectively balance and improve the non-uniform temperature distribution in the joints, resulting in the significant decreases in the peak temperatures and durations of high temperature. Hence, the grains are refined in the microstructure of the nugget zone in the UHaFSW joints, which enhances their microhardness and tensile properties. Based on these results, it can be concluded that UHaFSW could be an effective method to improve the mechanical properties of AZ31 magnesium alloy welded joints.
\end{abstract}

Keywords: friction stir welding; magnesium alloy; temperature; heat pipe; microstructure; mechanical property

\section{Introduction}

Friction stir welding (FSW) is a refreshing solid-state joining process, which was invented and developed by The Welding Institute (TWI) of United Kingdom in 1991 and obtained worldwide patents protection [1]. In comparison to other traditional welding technologies, FSW has the advantages of low cost, no pollution, little deformation of base materials after welding, high efficiency and so on, which can weld magnesium $(\mathrm{Mg})$ and aluminum (Al) alloys without melting. Hence, it can eliminate some problems related to the solidification. As such, FSW gradually become one of the most popular technologies in the welding of $\mathrm{Mg}$ and $\mathrm{Al}$ alloys and is widely used in aerospace manufacturing, ship manufacturing, rail transportation and artificial intelligence industry [2-5].

Generally, FSW is an extremely complex "coupled thermal-force" process, which involves a complex phenomenon related to severe plastic deformation, material movement, thermal softening, and heat transfer during the FSW process [6-9]. As a critical factor, the temperature directly affects the materials flow and the formation of joints, which in turn is closely related to the quality of the joints. A few specific works were carried out on the FSW-induced temperature field and indicated that the decrease in the welding temperature leaded to the better mechanical properties. Xu et al. [10] conducted rapid-cooling FSW to join AZ31B Mg alloy plates of $6 \mathrm{~mm}$ under liquid $\mathrm{CO}_{2}$ cooling and found ultrafine grains with high dislocation density were obtained in the weld which resulted in higher strength and elongation compared with the conventional friction stir welded (FSWed) 
joints. Mehta et al. [11] respectively conducted conventional and cooling assisted FSW on the join of $\mathrm{Mg}-\mathrm{Al}$ dissimilar alloy and also found that medium cooling enhanced the tensile strength of the FSWed dissimilar joints. Chowdhury et al. [12] pointed out that the welding temperature strongly influences the microstructure of welded joint; lower heat input leads to the higher strength and ductility due to the refined grains in the nugget zone of welded joint. Silva et al. [13] reported a kind of in-process cooling method using compress air, liquid nitrogen, and water during the FSW process and found in-process cooling with water was a more effective choice in processing AA7039 alloy; in-process cooling changed the fracture location from heat affected zone to nugget zone. However, other works also showed that too low heat input during FSW would lead to the lack of materials flow and formation in tunnel defect which decreased the mechanical properties of welded joints $[14,15]$. Hence, the control of the temperature or heat distribution during the FSW process is critical to obtain high-quality welded joints.

Recently, some researchers reported that using ultrasonic vibration as assisted auxiliary energy could decrease the heat generation, improve the materials flow, eliminate the tunnel defect and refine the welded microstructures in the nugget zone of similar and dissimilar $\mathrm{Al}$ alloy joints during the FSW process, which increased their mechanical properties [16-18]. Furthermore, Shi et al. [19] reported that the ultrasonic vibration reduced the contact shear stress at the tool-workpiece interface, which lead to relatively lower heat generation rate and improvement in material flow around the stirring tool during the FSW process. Liu et al. [20] joined the AZ31B Mg and 6061-T6 Al alloys by ultrasonic-assisted FSW at low temperature and obtained a smooth $\mathrm{Al} / \mathrm{Mg}$ joint with potential tensile strength and elongation which reached $134 \mathrm{MPa}$ and 1.5\%, respectively. However, Zhong et al. [21] conducted ultrasonic-assisted FSW on an AA2024-T3 alloy and found the thermal effect of ultrasonic vibration on the peak temperature was negligible based on the measurement of thermal cycle curves. Thus, to summarize the studies mentioned above, ultrasonic vibration is still insufficient in the control of welding temperature.

In the FSW process, heat is generated by friction between the tool and the workpiece. During a complete FSW process, both recovery and recrystallization phenomena take place simultaneously [22]. With the increase of the welding distance, the heat accumulates continuously. The heat that does not dissipate in time results in local overheating, which leads to grain-coarsening in the weld $[2,5,7]$. In order to restrain grain coarsening, heat generation should be reduced by cooling. A heat pipe is a very effective device for transferring heat at high rates over considerable distances with the advantages of extremely small temperature drop, exceptional flexibility, simple construction, and easy control with no external pumping power [23]. As a highly-effective heat transfer element, heat pipes have been gradually applied and play an important role in almost all industrial fields [24,25]. Faghri and Guo [26] integrated two kinds of heat pipes into fuel cells and found all heat pipes improved thermal control effectively in the fuel cell stack. Antariksawan et al. [27] conducted the straight heat pipe (SHP) in a water cooling tank (WCT) and found that the given SHP could transfer the heat from the WCT to a heat sink and prevent a continuous increase in the temperature of WCT. Furthermore, using a heat pipe to control the temperature in the FSW process was studied by Lu et al. [28,29], where the heat pipe decreased the peak temperature during the FSW process and promoted the tensile property of welded AZ31 $\mathrm{Mg}$ alloy joints. Due to the highly-effective heat dissipation of the heat pipe, the excessive heat can be effectively taken away, which leads to better uniformity of the temperature field along the whole weld. Hence, on the basis of ultrasonic assisted FSW, the application of heat pipe may enhance the temperature control during the welding process, which is suggested to play a positive role in the quality of welding joints.

Up to date, most works with respect to the temperature field during the FSW process focus on Al-based alloys. There are few investigations on the temperature distribution of $\mathrm{Mg}$ alloys during the FSW process, especially on the temperature control of $\mathrm{Mg}$ alloy joints. In this work, AZ31 Mg alloy plates were used as experimental materials and welded by FSW. The welding thermal cycle curves of AZ31 Mg alloy were measured by 
means of embedding thermocouples in welded workpieces under three FSW conditions: conventional FSW (FSW), ultrasonic assisted FSW (UaFSW), and ultrasonic and heat pipe coordinately assisted FSW (UHaFSW), respectively. The welding temperatures were deeply investigated and their influences on the microstructures, hardness, tensile properties and fracture morphologies of the joints were further discussed.

\section{Materials and Methods}

\subsection{Materials}

Rolled AZ31 Mg alloy was selected as FSW material with the workpiece's size of $200^{\mathrm{L}} \times 85^{\mathrm{W}} \times 4^{\mathrm{T}} \mathrm{mm}$. Its composition is listed in Table 1 .

Table 1. Chemical compositions (wt. \%) of AZ31 Mg alloy.

\begin{tabular}{ccccccccc}
\hline $\mathbf{A l}$ & $\mathbf{S i}$ & $\mathbf{C a}$ & $\mathbf{Z n}$ & $\mathbf{M n}$ & $\mathbf{F e}$ & $\mathbf{C u}$ & $\mathbf{N i}$ & $\mathbf{M g}$ \\
\hline 3.240 & 0.024 & 0.002 & 1.140 & 0.313 & 0.008 & 0.001 & 0.002 & Bal. \\
\hline
\end{tabular}

FSW was conducted using a friction stir welding machine as shown in Figure 1. The machine (FSW-3LM-002) consisted of gantry type computer numerical control (CNC) architecture, spindle motor, moving table, and human-machine interactive (HMI) control interface (Figure 1a). In this work, the AZ31 workpieces were placed and welded on the working table (Figure 1b) with the stirring tool, which was made of $\mathrm{H} 13$ steel, with a concave shoulder $16 \mathrm{~mm}$ in diameter and a threaded tapered pin $3 \mathrm{~mm}$ in diameter and $3.85 \mathrm{~mm}$ in length (Figure 1c). Besides, the ultrasonic vibration system (consisted of ultrasonic generator and ultrasonic oscillator) and the flat heat pipe system were used in the FSW experiments. The self-designed temperature measuring pads, paperless recorders (Yokogawa Electric Corporation, Guangzhou, China), and armored thermocouples (TC) were used to record the thermal cycle curves.

\subsection{Methods}

Before FSW, the welding and butt surface of AZ31 Mg alloy workpieces were ground and polished to remove the oxides and contaminations. All the workpieces were designed to measure the thermal cycle curves by embedding thermocouples at different locations along the welding direction under three FSW conditions, respectively. The measuring parts of the thermocouples were plunged from the bottom plate into the workpieces to make close contact with each other. In order to get the thermal cycle curves as close to the welding center as possible, and avoid the thermocouples from moving during welding, the distance between the thermocouples and weld center was designed to be $3 \mathrm{~mm}$, and the depth inserted into the workpiece by each thermocouple was $2 \mathrm{~mm}$, as well as the width. The distribution of feature points (point 1 to point 7 ) for measuring the thermal cycle curves and the setting position of the thermocouples in cross section of the workpieces are illustrated in Figure 2b,c. Like the other FSW process, the workpieces were fixed on the work table of the machine and the rotating stirring tool was inserted into the joint and welded along the pre-designed route [11]. During the UaFSW process, the ultrasonic tool was placed toward the weld $50 \mathrm{~mm}$ behind the starting location of stirring tool and moved with the stirring tool. The angle between the ultrasonic tool and the horizontal plane was $30^{\circ}$. The model of the ultrasonic generator was T JS-3000 V6.0, the power was $500 \mathrm{~W}$, the frequency was $20 \mathrm{KHz}$, the power input was $\mathrm{A} 220-250 \mathrm{~V} 5 \mathrm{~A}$, and the working environment was $0{ }^{\circ} \mathrm{C}-40{ }^{\circ} \mathrm{C}$. For the condition of UHaFSW, flat heat pipes (made of pure copper) were placed parallel on the upper surface of the workpiece along the welding direction associated with ultrasonic assistance, as shown in Figure 2a. The distance between the two heat pipes was $24 \mathrm{~mm}$, which was slightly wider than the FSW shoulder $(16 \mathrm{~mm})$ to avoid contact with each other. In addition, to ensure a good contact between the heat pipe and the workpiece, a layer of heat-conducting silicone grease was manually coated on the lower surface of each heat pipes. In UHaFSW process, ambient temperature water of about $20{ }^{\circ} \mathrm{C}$ was applied to the cooling tank by the water supply system at the beginning, aiming to start welding and 
heat dissipation by heat pipes at the same time, and the level of circulating water in the cooling tank basically kept in a steady state by manually adjusting the flow of the water supply system during the whole welding process. Joining was processed at the optimized parameters by our research group as listed in Table 2 to avoid conventional welding defects such as tunnel formation, cavities, and cracks in the welding zone.
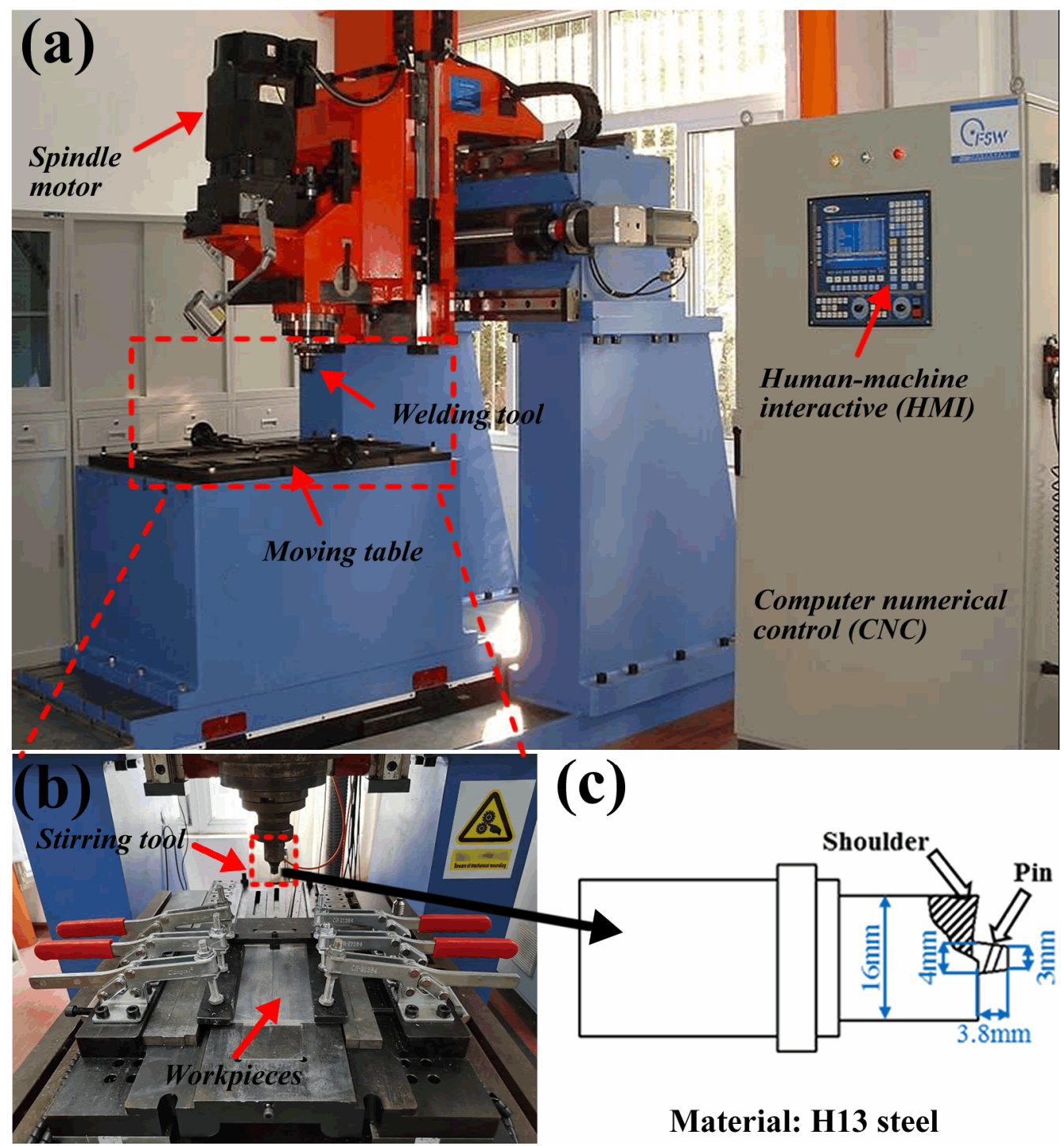

(c)

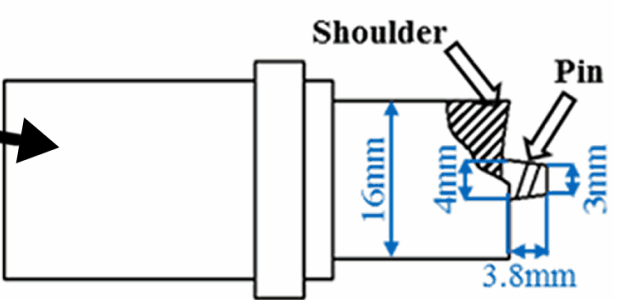

Material: H13 steel

Figure 1. FSW equipment and stirring tool used in this work: (a) welding machine, (b) working table and (c) schematic illustration of stirring tool.

Table 2. Welding parameters for AZ31 Mg alloy workpiece.

\begin{tabular}{cc}
\hline Parameters & Values \\
\hline Rotational Speed & $1500 \mathrm{rpm}$ \\
Welding Velocity & $50 \mathrm{~mm} / \mathrm{min}$ \\
Pin Length & $3.85 \mathrm{~mm}$ \\
Shoulder Diameter & $16 \mathrm{~mm}$ \\
Pin Diameter & $3 \mathrm{~mm}$ \\
Tilt Angle & $2.5^{\circ}$ \\
\hline
\end{tabular}




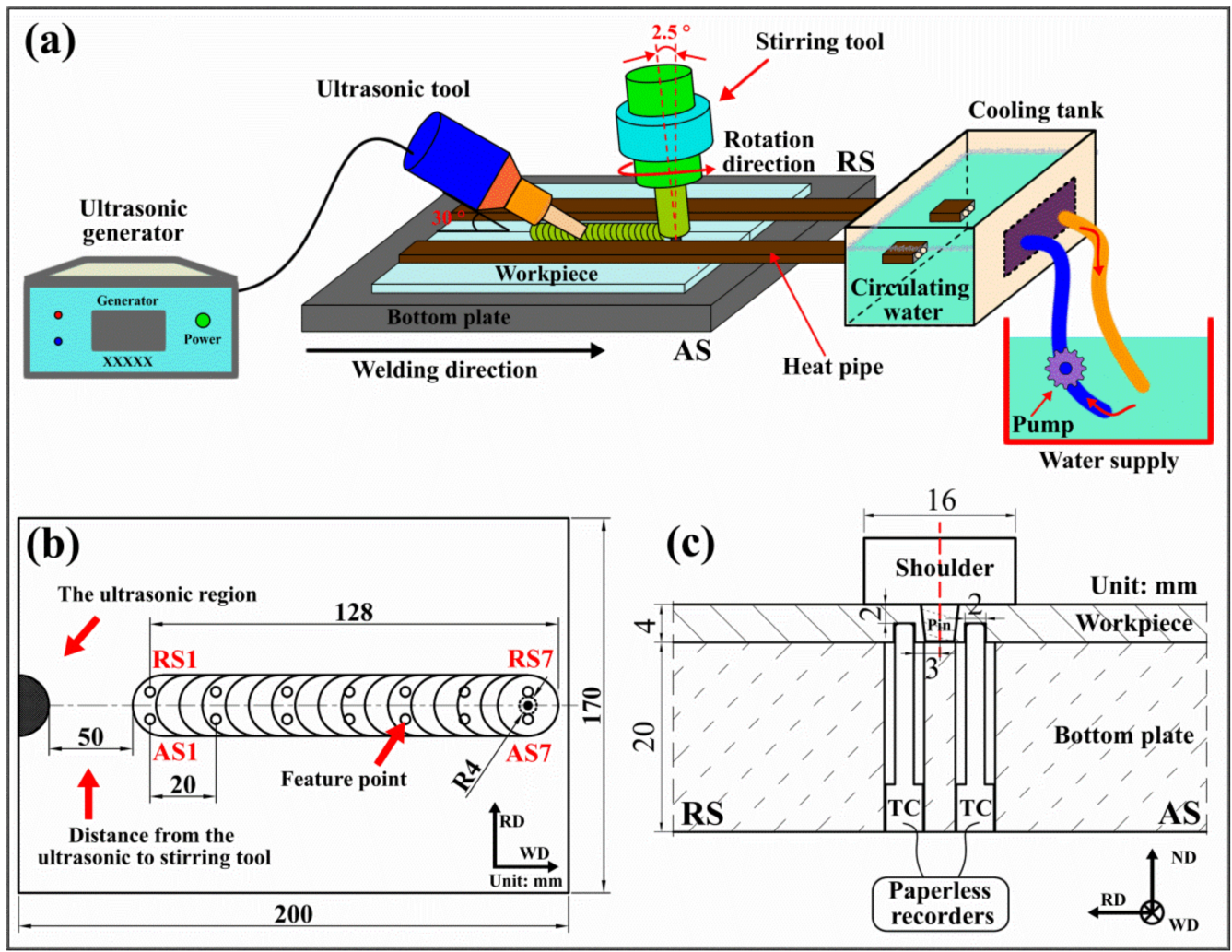

Figure 2. The schematic diagrams of welding and temperature measurement design: (a) ultrasonic and heat pipe assisted FSW process, (b) distribution of feature points for thermal cycle curve measurement and the location of the ultrasonic tool (where RD is the rolling direction of AZ31 Mg alloy sheet and WD is the welding direction of the joint), and (c) the section of thermal cycle curve measurement (where ND is the normal direction). AS and RS indicate advancing side and retreating side.

After joining, the welded workpieces were cut into small specimens in the middle region of welded joints. The cross sections of these specimens were then metallographically ground with different graded $\mathrm{SiC}$ papers followed by polishing using diamond paste. The polished specimens were etched by a mixed solution comprising $5.0 \mathrm{~mL}$ nitric acid, $2.0 \mathrm{~g}$ oxalic acid, and $100 \mathrm{~mL}$ distilled water, and then rinsed by ethanol. The average grain size in the nugget zone were measured by the mean liner intercept method according to the ASTM E112-13 [30]. The cross-sectional macrostructures and microstructures of etched specimens were observed by ultra-depth 3D microscope (VHX-900, Keyence Osaka, Japan) and Zeiss metallographic optical microscope (ZeissAxioskop2-MAT, Oberkohen, Germany). Microhardness measurements were carried out by Vickers indentation method (KB-30S, Hochdorf-Assenheim, Germany) across the cross section of welded joints by applying $200 \mathrm{~g}$ load for $20 \mathrm{~s}$ on three parallel samples obtained from advancing side across the joint to retreating side, which included four different zones of base metal (BM), heat affected zone (HAZ), thermo-mechanically affected zone (TMAZ), and nugget zone (NZ). The distance between points and parallel lines were $0.5 \mathrm{~mm}$ and $1.0 \mathrm{~mm}$, respectively. Besides, the distance from the top or bottom surface to the corresponding point was also $1.0 \mathrm{~mm}$ (as illustrated in Figure 3a). Five standard tensile specimens of BM and welded joint (as illustrated in Figure 3b) under three FSW conditions were conducted for uniaxial tensile test to determine the average tensile properties at a constant displacement rate of $2.0 \mathrm{~mm} / \mathrm{min}$ by a universal testing machine (CMT5205, Mechatronic Control Systems, Shanghai, China). Tensile tests were carried out perpendicular to the welding direction (WD) at room temperature. The specimens were prepared according to the GB/T 168652013 standard (as illustrated in Figure 3c). After tensile test, the fracture morphologies of the 
specimens were examined by SEM (Shimadzu, JSM-6480, Kyoto, Japan) for investigating the fracture modes.
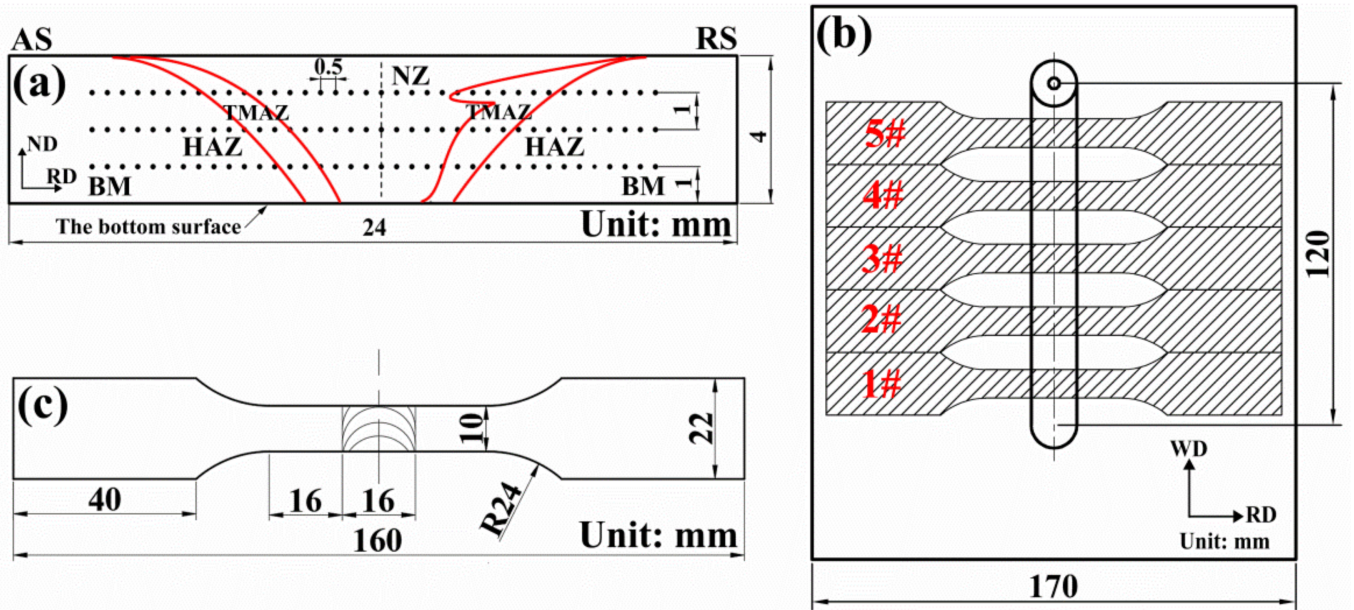

Figure 3. Illustration of (a) the selection of the points for hardness test across the whole welded joint for micro-hardness test, (b) the selection of tensile specimens, and (c) the dimension of tensile specimens.

\section{Results and Discussion}

\subsection{Thermal Cycle Curve and Temperature Distribution}

\subsubsection{Thermal Cycle Curve with Dual Peaks Phenomenon}

Figure 4 shows the thermal cycle curves of feature points on both advancing side (AS) and retreating side (RS) under FSW, UaFSW, and UHaFSW conditions in the initial stage (including points 1 and 2), middle stage (including points 3, 4, and 5) and finishing stage (including points 6 and 7). As seen from Figure 4, the trends of each thermal cycle curve in three welding conditions are basically similar, including the "heating up-reaching the peak-cooling down" process. Along the welding direction, the initial stage goes through the whole "heating up-reaching the peak-cooling down" process earlier than the middle stage and finishing stage. Such a finding indicates that the temperature change in each feature point was not synchronous and the temperature distribution of all samples were "non-uniform" along the welding direction. It can be understood that the stirring tool was inserted into the workpiece with a high rotational speed at the beginning and heat was generated by the friction between the stirring tool and the workpiece. Therefore, the temperatures of the feature points (AS1, RS1, AS2, and RS2) increased at the initial stage. However, because of the cooling and heat dissipation, the heat generation had little influence on feature points far away from the friction location. During the FSW process, the stirring tool, as a mobile heat source, continuously heated the feature points surrounded. As this heat source approached, the temperatures of the feature points in front of the stirring tool started to rise. The closer to the tool, the faster the temperature rose. On the contrary, the temperatures of the feature points behind the stirring tool started to decline because of the increased distance to the stirring tool. Such a situation caused the nonsynchronous change in the temperatures of feature points at different locations. Besides, almost all of the peak temperatures of feature point 7 went down except the two feature points on the retreating side at the finishing stage under FSW and UaFSW conditions (Figure 4b,d). This could be because the decline and termination of heat generation result in the decrease in the peak temperature on the advancing side at the finishing stage during the pulling out process of the stirring tool. However, due to the materials flow, the heat is carried from the advancing side to retreating side by stirring tool, which leads to the increase in the peak temperature of feature point 7 on the retreating side. With the application of the heat pipe, the peak temperature of feature point 7 decreases on the retreating side under the UHaFSW condition, which is attributed to the efficient heat transfer of heat pipe. 

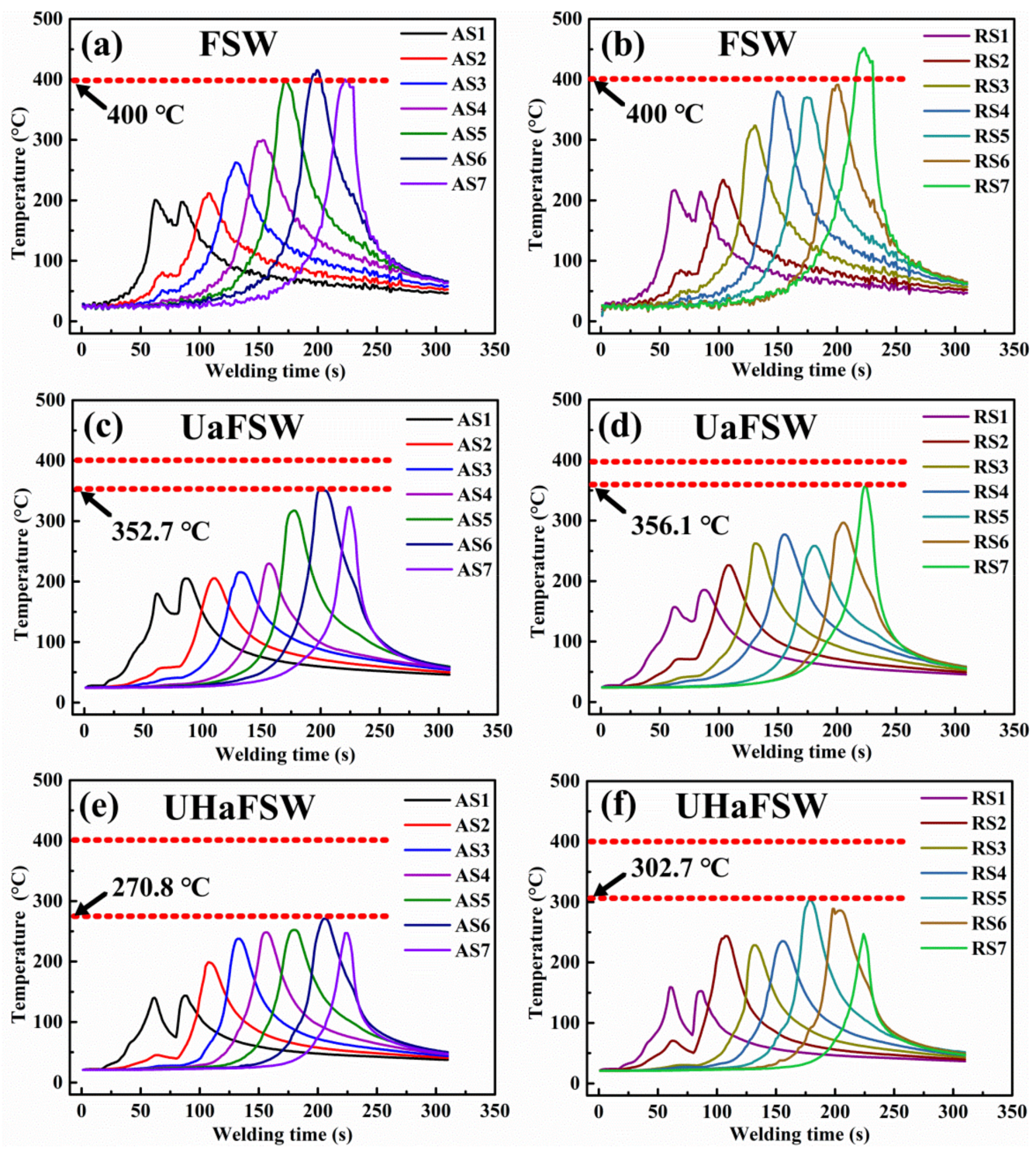

Figure 4. Thermal cycle curves of feature points of advancing side (AS) and retreating side (RS): (a) AS under the FSW condition, (b) RS under the FSW condition, (c) AS under the UaFSW condition, (d) RS under the UaFSW condition, (e) AS under the UHaFSW condition, and (f) RS under the UHaFSW condition.

Due to the application of ultrasonic and heat pipe, the peak temperature of each feature point during the UaFSW and UHaFSW process is generally lower than the corresponding one during the FSW process; the maximum peak temperature exceeds $400{ }^{\circ} \mathrm{C}$ during the FSW process while it reaches $350{ }^{\circ} \mathrm{C}$ and $300^{\circ} \mathrm{C}$ in UaFSW and in UHaFSW, respectively (indicated by arrows in Figure 4). It specifies that the assistance of the ultrasonic and heat pipe can effectively reduce the heat generation and heat accumulation during the FSW process and therefore the peak temperature at each feature point decreases. Due to the vibration effect, thermal effect, and volume effect during ultrasonic transmission, the yield strength and rheological stress of the base metal decrease during the FSW process, leading to the localized softening and the facilitation of materials flow and plastic deformation [17,31]. On the other hand, according to the related studies [18,19], ultrasonic reduces the friction between the tool and the workpiece, which leads to a reduction in the heat generation. Hence, the maximum peak temperature declines in the UaFSW process. Moreover, due to the highly efficient heat transfer of heat pipe, a large amount of waste heat generated by FSW is quickly transferred away. The effective reduction in the heat accumulation of 
the welded joints leads to a further decline in the peak temperature during the UHaFSW process. Meanwhile, it is also found that the overall peak temperatures are more uniform during the UHaFSW process due to the heat transfer effect of heat pipe. The maximum temperature difference between the feature points is $143.7^{\circ} \mathrm{C}$ in UHaFSW, which is lower than those in FSW $\left(234.9^{\circ} \mathrm{C}\right)$ and in UaFSW $\left(170.6^{\circ} \mathrm{C}\right)$. In this case, the heat pipe can take away a large amount of waste heat during the welding process, which leads to the decrease and uniformity in the peak temperatures, thereby balancing the temperature distributions along the welding direction.

As shown in Figure 4, two peaks are obviously found in the curves of both AS1 and RS1 under three conditions. This phenomenon is named "dual peaks phenomenon" in this work. It is related to the heat generation and transmission due to the insertion of the stirring tool in the initial stage [32]. At the very beginning of the initial stage, the workpiece was placed in a room temperature environment and the inserted stirring tool quickly generated heat so that the first peak temperature was presented. However, the bottom of the workpiece and the table were still at lower temperatures. Heat was generated and dissipated simultaneously, which led to the decline of first peak temperature. When the stirring tool began to move along the welding direction, the tool pin stirred the material, which led to the heat generation and plastic deformation. Hence, the friction heat and deformation heat accumulated quickly at the very beginning, resulting in the second peak. Afterwards, the tool was far away the starting location and the temperature declinesd. Figure 5 shows the dual-peaks curves of both advancing side and retreating side under three conditions. Compared with FSW and UaFSW conditions, the welding temperature at the trough of curves on the advancing side and retreating side are only $75{ }^{\circ} \mathrm{C}$ and $80^{\circ} \mathrm{C}$, respectively, under UHaFSW (as indicated by red arrows), which is the lowest in three conditions (as indicated by green arrows). Due to the good heat dissipation effect of heat pipes, the heat generated by the friction between the stirring tool and the workpiece was quickly taken away, which led to a significant decline of the temperature at the trough. Furthermore, in the Ref. [33], it is observed that as the initial preheating temperature of workpieces increases, the yield strength decreases and as a result less forming force is required for deformation during FSW process and consequently less friction stress and heat were generated. Hence, although the effective heat dissipation of heat pipe leads to the reduce in the initial temperature of the workpiece, the thermal cycle curves at the initial stage still has the "double peaks phenomenon" in UHaFSW process due to the increase in the heat production.
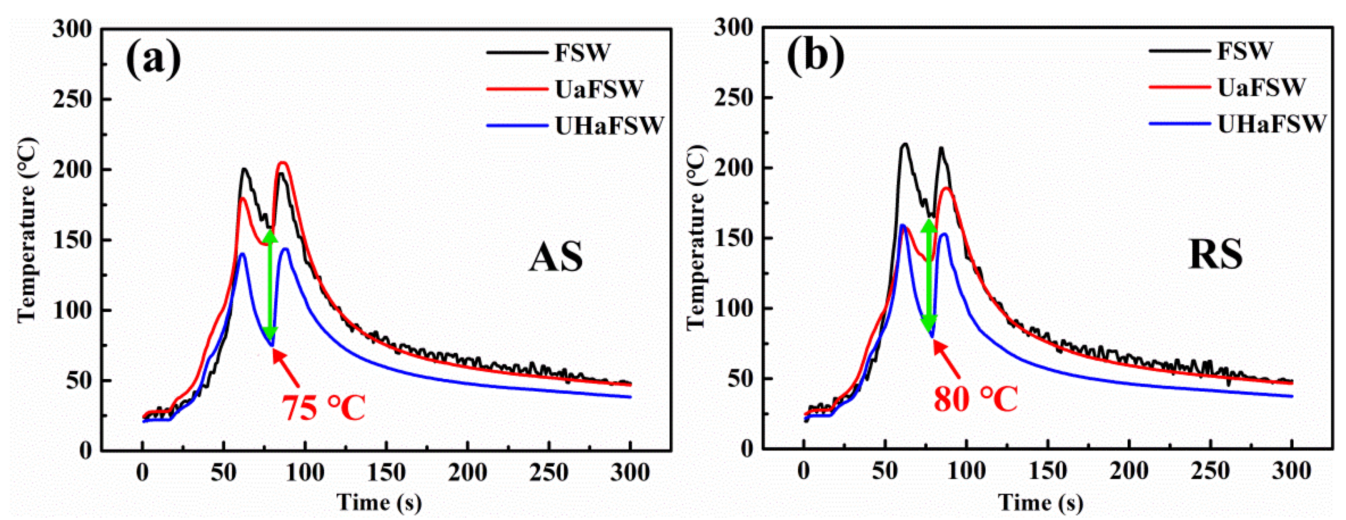

Figure 5. Dual-peaks curves under three welding processes: (a) advancing side (AS), (b) retreating side (RS).

\subsubsection{Non-Uniform Temperature Distribution}

Figure 6 reveals the distribution in the peak temperatures of feature points (\#1 to \#7) along welding direction on both AS and RS of joint in conventional FSW process and differences in the average peak temperatures of all feature points between two sides under three FSW conditions. Generally, the differences in the welding peak temperatures exist 
between AS and RS, which exhibits the "going up-reaching the peak-going down" process, as shown in Figure 6a. The maximum difference of the peak temperature between AS and RS is presented at the feature point 4 , which is over $80^{\circ} \mathrm{C}$ (indicated by the blue arrow in Figure 6a). It can be seen that there is a certain temperature difference between two sides of the joint, which leads to the nonuniformity in the welding temperature along the horizontal direction. According to the Refs. [2,5,34], FSW is an intrinsically asymmetric process due to the combined effects of the stirring tool movement and rotation, resulting in asymmetric distributions in the temperature and deformation rate. Commonly, considering the relative movement of the workpiece with respect to the tool rotation, the materials on the AS experience more severe shear deformation than that on the RS. Therefore, the difference in the effective deformation rate between AS and RS leads to the different temperature distributions. Furthermore, due to the more heat generation at the middle stage during FSW process, the temperature difference between the two sides of welded joint tends to be more obvious. Figure $6 \mathrm{~b}$ shows the average differences of overall peak temperatures between AS and RS. Obviously, compared with FSW, although the application of ultrasonic vibration decreases the peak temperature of the weld to a certain extent (Figure 4), the non-uniform temperature distribution is not improved along the horizontal direction. In UHaFSW, the non-uniform temperature distribution is obviously improved due to the enhanced heat dissipation and temperature control of the heat pipe. In addition, the temperature of the stirring tool also influences the temperature distribution in the workpiece. A stirring tool with higher thermal conductivity facilitates more effective heat dissipation, which promotes the reduction in the temperature in the nearby locations [7,34]. Therefore, the FSW system with higher thermal conductivity is prone to improve the non-uniform temperature distribution along the horizontal direction.
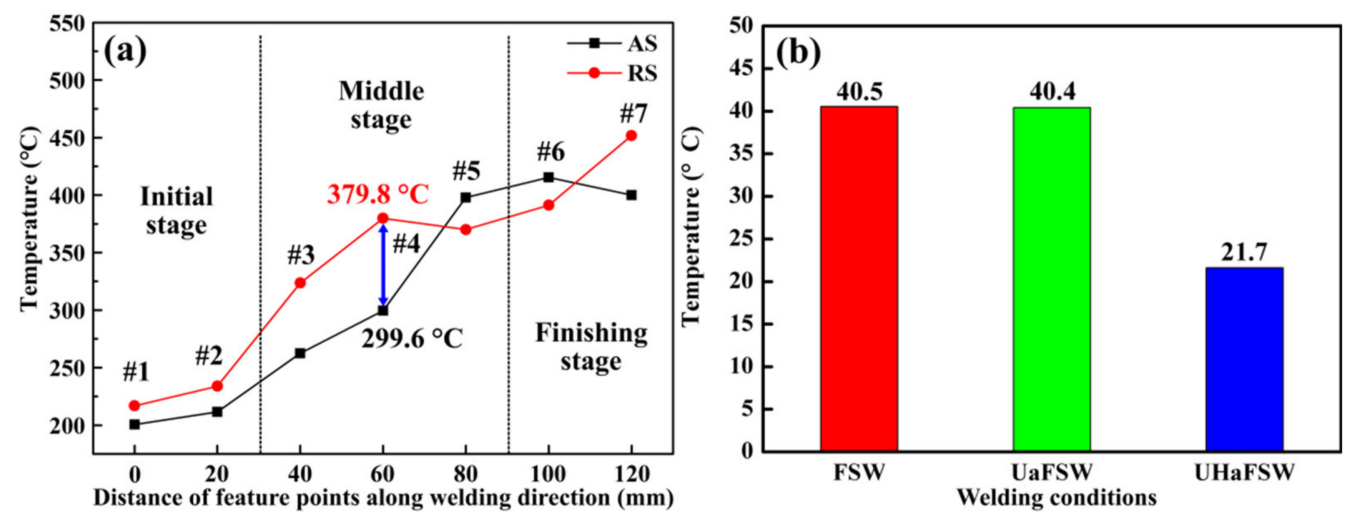

Figure 6. Comparison of peak temperatures of feature points (\#1 to \#7) on both sides under conventional FSW condition and average peak temperature differences under three FSW conditions: (a) peak temperatures on both sides of the joint along welding direction under conventional FSW condition, (b) average peak temperature differences between advancing side and retreating side under three FSW conditions.

\subsubsection{Duration and Effect of High Temperature}

As it is well known that heat is generated by the friction between the stirring tool and workpiece and via plastic deformation during the FSW process, a fraction of plastic deformation energy is stored in the thermos-mechanically deformed region in the form of increased defect densities [8,35]. Besides, during severe deformation, the recovery and recrystallization often take place simultaneously in the materials [22,36]. According to a previous study [37], the dynamic recrystallization temperature of $\mathrm{Mg}$ alloy is about $200{ }^{\circ} \mathrm{C}$. Therefore, the retaining time over $200^{\circ} \mathrm{C}$ is defined as "the duration of high temperature", which is considered as a period for the nucleation and growth of recrystallized grains in the experimental materials. Generally, the recrystallized grains would coarsen due to the higher welding temperature or longer duration of high temperature, which leads to the decline in the mechanical strength of joints. 
Calculating from the thermal cycle curves, the durations of high temperature for the selected feature points (AS2 to AS7) under three FSW conditions are shown in Figure 7. Figure $7 \mathrm{a}$ shows the definition of the duration of high temperature. In Figure $7 \mathrm{~b}$, it is found that the duration of high temperature firstly increases and then decreases for AS2 to AS7 under three FSW conditions, which is consistent with the variation in the peak temperatures of welding thermal cycle curves analyzed above (Figure 4). During the FSW process, the duration of high temperature is significantly longer than those in the UaFSW and UHaFSW process. Meanwhile, the difference in the duration of high temperature between AS2 and AS6 is the largest in FSW. For instance, the duration of high temperature for AS6 is about $51 \mathrm{~s}$ longer than that for AS2 in FSW. In comparison, such differences in UaFSW and UHaFSW are $31 \mathrm{~s}$ and $23 \mathrm{~s}$, respectively. Due to the increase in the duration of high temperature, more energy is provided for the recrystallization of the deformed materials, which leads to the grain coarsening of welded joints and extension in the heat affected zone [38]. In UHaFSW, the duration of high temperature is significantly reduced in whole welding process. For example, the durations of the feature points AS3, AS4, AS5, and AS6 in UHaFSW are shortened by $1 \mathrm{~s}, 1 \mathrm{~s}, 9 \mathrm{~s}$, and $15 \mathrm{~s}$, respectively, as compared to those in UaFSW. The shortening in the duration of high temperature substantially inhibits the grains coarsening of welded joints.
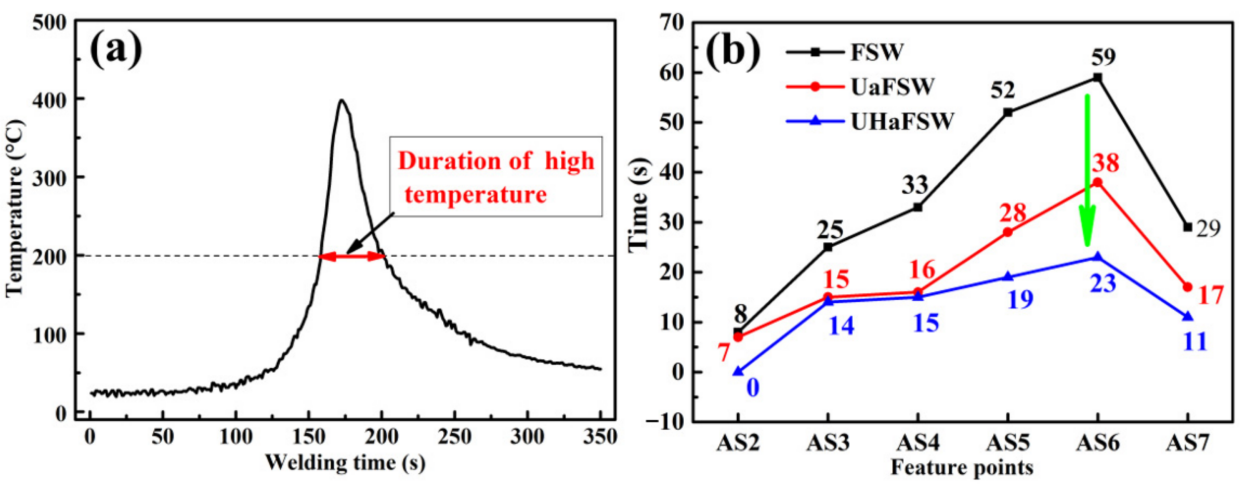

Figure 7. Duration of high temperature: (a) calculated schematic, (b) durations of high temperature at each feature point under three conditions.

\subsection{Microstructure}

Figure 8 is the optical images at the cross section of AZ31 joints in the middle stage of the welded workpiece under three FSW conditions. The region enclosed by red lines is the nugget zone. It is found that the profiles of nugget zones of three welded joints are similar to a typical "shallow funnel", which is wide at the top and narrow at the bottom. Obviously, due to the rotation and friction of tool shoulder, the materials at the top of the workpiece flow sufficiently and experience severe plastic deformation, which leads to the formation of wider region after the FSW process. In contrast, the material at the bottom is merely rotated by the tool pin with moderate plastic deformation, which results in a narrow region. After measuring the width of the nugget zone at the top, middle, and bottom, respectively, it can be seen that compared with the FSW process, the width of the whole nugget zone obviously expands under UaFSW since the ultrasonic vibration leads to the materials softening and thereby the increase in the plastic deformation (Figure 8b) [18]. In Figure 8a,c, probably due to the fast heat dissipation at the workpiece's surface, the width at the top of the nugget zone is narrower in UHaFSW than that in FSW, while it is opposite at the middle-bottom of the nugget zone probably due to the ultrasonic effect. Besides, it is quite interesting to carefully focus on the regions framed by the white dotted lines in three welded joints as shown in Figure 8 (indicated by logo I, II, and III), which actually represent the transition regions under the common influence of the stirring shoulder and the pin. In FSWed joint, a distinct corner towards to the NZ can be observed on the RS but not on the AS (Figure 8a) due to the asymmetrical "coupled thermal-force" process which 
causes asymmetrical plastic deformation [6]. However, this phenomenon is not evident significantly in UaFSWed and UHaFSWed joints (Figure 8b,c), which again indicates the influence by ultrasonic vibration and heat pipes.

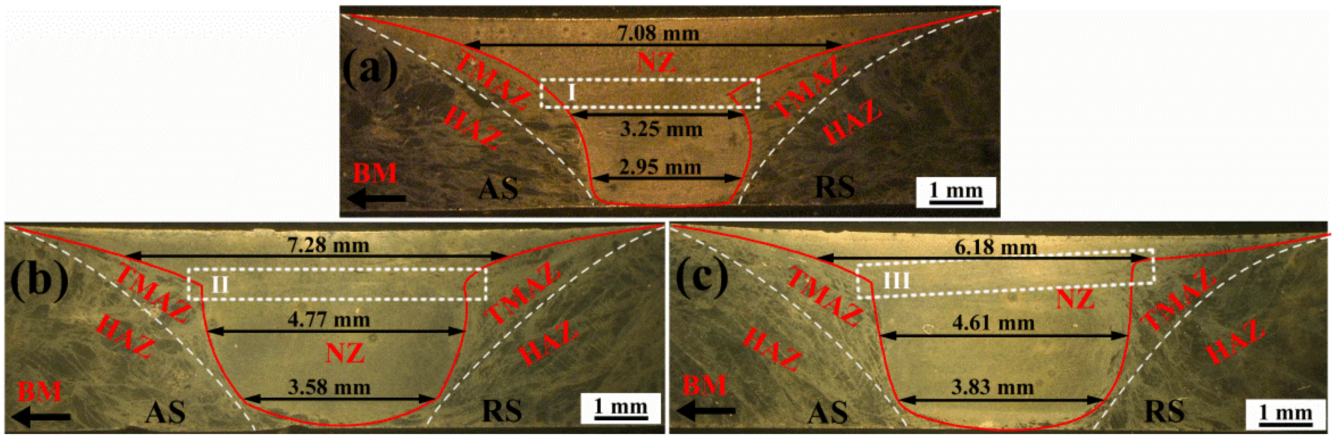

Figure 8. Optical images of FSWed AZ31 joints at the cross section under three conditions: (a) FSW, (b) UaFSW, and (c) UHaFSW.

Figure 9 shows the microstructure of base metal and the microstructures of the samples collected at the nugget zone under three FSW conditions. As seen in Figure 9b, the initial microstructure of rolled AZ31 Mg alloy used in this work consists of deformed and somewhat elongated grains with various sizes, which are coarsening, non-uniform, and discontinuous. However, after welding process, the refined grains could be clearly found in the nugget zone where the grains are more uniform (Figure 9c-e). The average grain sizes are $13.8 \mu \mathrm{m}$, $9.3 \mu \mathrm{m}$, and $9.1 \mu \mathrm{m}$, respectively, under three FSW conditions. Generally, FSW with the optimized parameters leads to the grain refinement in the nugget zone due to the severe plastic deformation and dynamic recrystallization [39-41]. However, it is reported that the small recrystallized grains in the nugget zone contain the high density of sub-boundaries, sub-grains, and dislocations [42,43]. Metallic material with such a microstructure often exhibits improved strength and hardness $[44,45]$. Likewise, the continuously generated heat leads to the increase in welding temperature during the FSW process. Above $200{ }^{\circ} \mathrm{C}$, the recrystallization of AZ31 Mg alloy would take place. According to the Ref. [10], the higher temperature leads to the easier dynamic recrystallization; nevertheless, the ability of grain boundary migration increases, which results in grain coarsening. Furthermore, the cooling rate after deformation plays an important role on the microstructure as well, it is easier to obtain fine grains with higher cooling rate. As mentioned above, the efficient heat dissipation of heat pipe leads to the decrease in peak temperature and the increase in cooling rate. Due to the obvious decrease in peak temperature and the duration of high temperature, the grain coarsening is effectively inhibited in the UHaFSW process, which results in the refined equiaxial grains in the nugget zone (Figure 9e). On the other hand, ultrasonic vibration effectively breaks downs the coarsened grains into refined grains during the welding process.

Figure 10 shows the optical images of the interfaces between the NZ and the TMAZ of AS and RS under three FSW conditions (indicated by red dotted lines, and the chosen regions as shown in Figure 9a). It is obvious that the interface of the UHaFSW joint (Figure 10e,f) is smoother than those of other welded joints. Especially on RS, a visible bulge structure is formed and found under FSW condition (Figure 10b). Furthermore, under UaFSW and UHaFSW conditions, the interfaces between the NZ and the TMAZ on both sides are more symmetrical than that of FSW condition. Meanwhile, the interfaces on AS were almost perpendicular to the horizontal direction (HD) in the UaFSW and UHaFSW joints (Figure 10c,e); however, the angle between the interface and the horizontal direction is just around $50.1^{\circ}$ on AS under the FSW condition (Figure 10a), which is very close to the shear fracture angle of normal tensile specimens [42]. Generally, FSW is an asymmetric process in the temperature and force. On one hand, the intensity of materials flow and mixture on RS is higher than that of AS, on the other hand, the difference in the 
welding temperatures exists between AS and RS, these phenomena result in the asymmetric interfaces between the NZ and the TMAZ on both sides, which leads to the defects tend to occur at the region between the NZ and the TMAZ $[7,38]$. Under the UaFSW and UHaFSW conditions, the improvement in the asymmetric interfaces on both sides is prone to the decrease in the occurrence of defects between the NZ and the TMAZ. Meanwhile, due to the decrease in the heat input, the reduction in the regions suffers the heat and severe deformation, leading to the almost perpendicular interfaces to the horizontal direction in UHaFSW process. The smoother, more symmetrical and more vertical interface indicates that the better materials flow and the heat transmission are probably obtained by the synergetic application of ultrasonic and heat pipe.
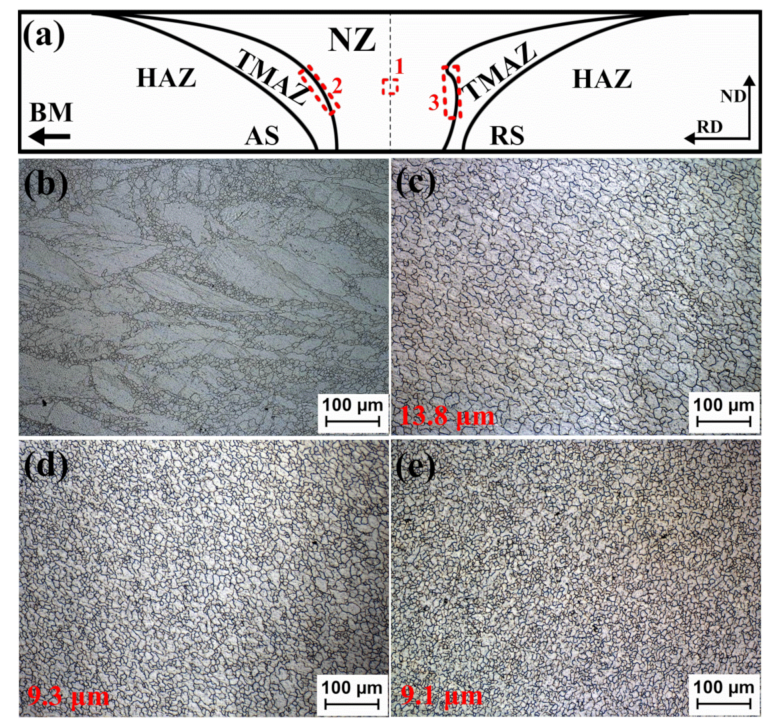

Figure 9. Optical images at different conditions: (a) the schematic diagram of the microstructures selection for analysis in the middle region of welded joints (where 1 is the microstructure in NZ, 2 and 3 are the interfaces between the NZ and the TMAZ), (b)AZ31 base microstructure, nugget zone microstructures under the conditions of (c) FSW, (d) UaFSW, and (e) UHaFSW.

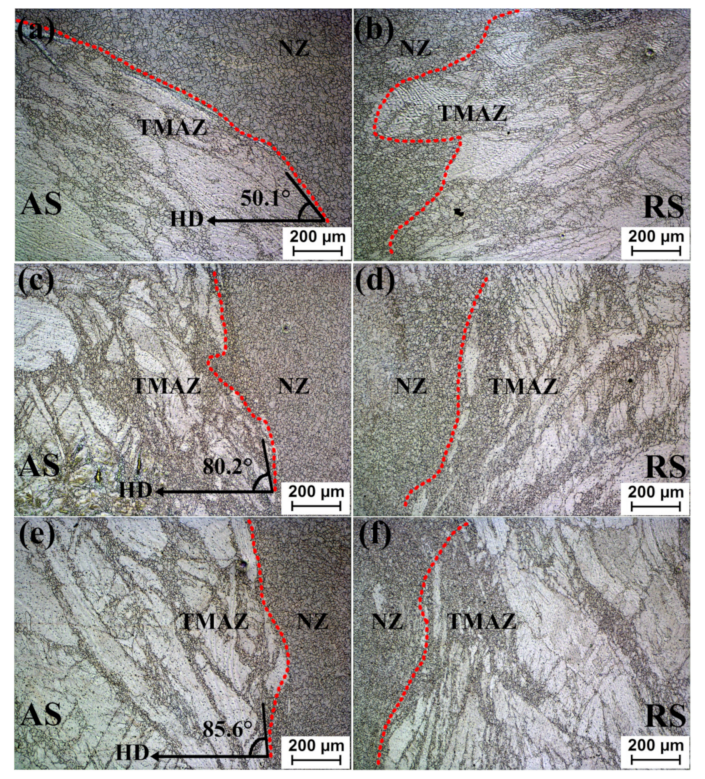

Figure 10. Optical micrographs of the interfaces between the NZ and the TMAZ of advancing side (AS) and retreating side (RS) chosen in the middle region of welded joints: (a) AS under FSW condition, (b) RS under FSW condition, (c) AS under UaFSW condition, (d) RS under UaFSW condition, (e) AS under UHaFSW condition, and (f) RS under UHaFSW condition. 


\subsection{Microhardness}

Figure 11 shows the microhardness profiles along three lines across the welded joints chosen at the middle stage during the welding processes and their quantile distribution under three FSW conditions. Compared with the base metal, the hardness across the whole welded joints declined under the FSW condition, the hardness distribution profile across the whole welded joint presents a " $\mathrm{W}$ " pattern, and the lowest hardness positions are presented between TMAZ and NZ (Figure 11a), which is consistent with outcomes in the Refs. $[12,29,46]$. Generally, the deformed metallic materials undergo the static recovery, recrystallization ( $\mathrm{T} \geq 0.5 \mathrm{~T}_{\mathrm{m}}, \mathrm{T}_{\mathrm{m}}$ is the melting point) and other softening processes during annealing or heating, which results in a decrease in hardness [6,36]. Besides, temperature plays a very important role in the softening process, the higher the temperature, the faster the occurrence of recovery and recrystallization. As mentioned above, rolled AZ31 Mg alloy was selected as an FSW material in this work. Hence, affected by the generated heat during FSW process, a static recovery occurs in the HAZ of the FSWed joint [22]. However, due to the short duration of high temperature (as shown in Figure 7), the process of the static recovery is quite insufficient, resulting in the slight decrease in hardness across the whole HAZ. Likewise, varying degrees of dynamic recovery and recrystallization occur in the TMAZ and NZ due to the simultaneous deformation and high temperature under the FSW process. The occurrence of dynamic recovery and recrystallization reduces the dislocation density and stored energy in metallic materials, which leads to the decreases in the strength and hardness of metals and alloys but increase in their plasticity [37,47]. However, dynamic recrystallization in the NZ results in the grain refinement in turn, which increase the hardness of softened materials to some extent. Such a process presents the special "W" pattern of the hardness distribution profile across the whole welded joint of AZ31 Mg alloy.
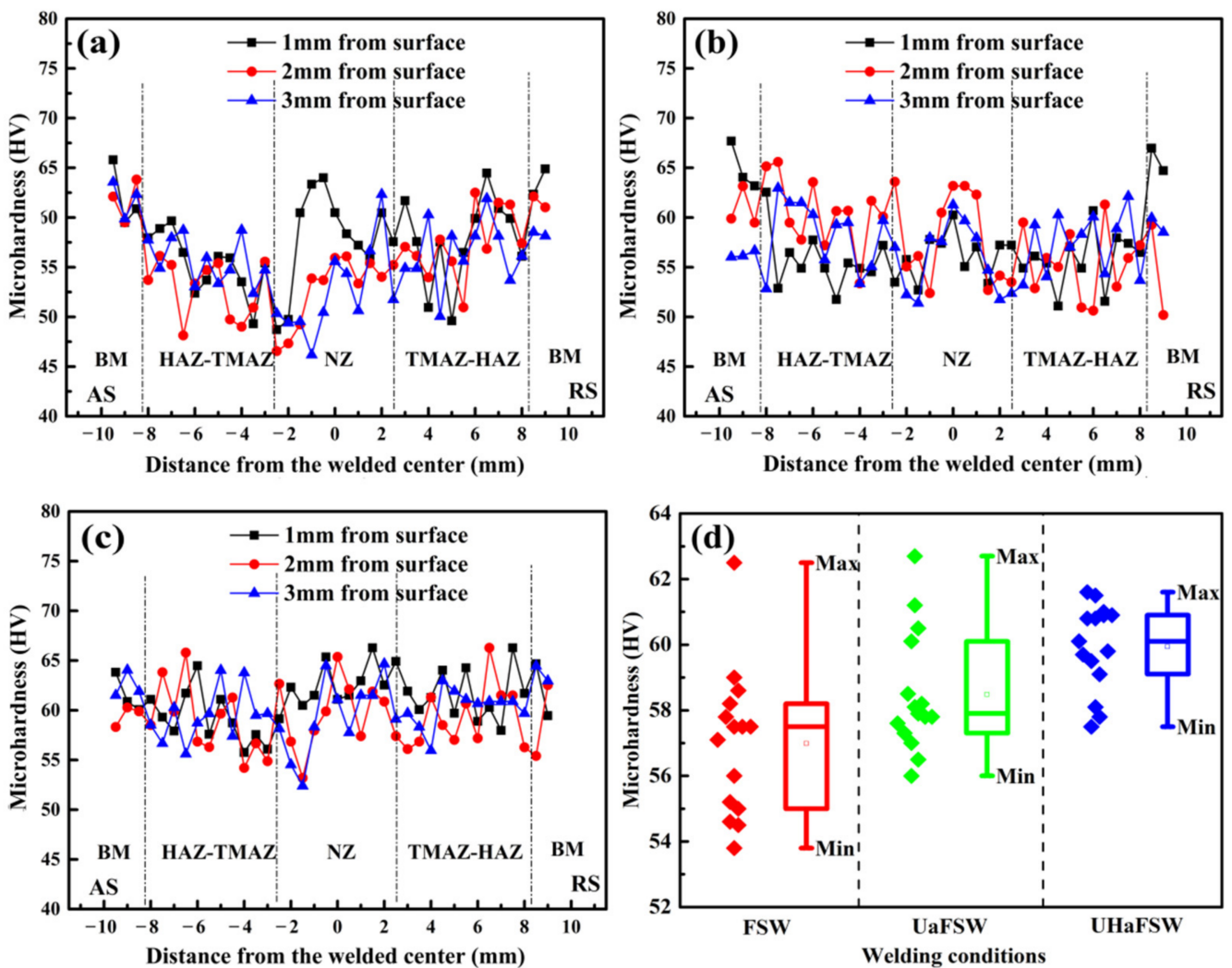

Figure 11. Microhardness obtained by measuring across the welded joints at the middle stage during welding processes as well as their quantile distribution: (a) FSW, (b) UaFSW, (c) UHaFSW, and (d) quantile distribution. 
Interestingly, with the application of ultrasonic and heat pipe, concentrated microhardness values indicate the better uniformity of the welded joints. Especially under the UHaFSW condition, the original " $\mathrm{W}$ " pattern of the hardness distribution profile is almost absent (Figure 11c). Furthermore, compared with other FSW conditions, the overall average microhardness of joint produced by UHaFSW increases about $5.2 \%$ and $2.5 \%$, respectively (Figure 11d). It specifies that grain refinement plays a significant role in strengthening of AZ31 Mg alloy joint and the grains tend to be finer when the heat input is limited during the welding process [6]. Under the UHaFSW condition, due to the effective heat transfer and dissipation by heat pipe, the obvious decrease in the peak temperature and duration of high temperature leads to the minimum heat input. As described in the Ref. [12], the hardness of NZ in the weld is mainly associated with the heat input during FSW and the ensuing change in the grain size; the microstructure with a smaller grain size would have a higher hardness or strength. In UHaFSW process, the lowest peak temperature corresponds to the lowest heat input, resulting in the smallest grain size in the NZ that culminates to a higher hardness distribution in the weld. Hence, the lower heat input restrains the grains' coarsening, resulting in the increase in hardness.

\subsection{Tensile Properties and Fractographies}

The tensile properties of the BM and the welded AZ31 Mg alloy joints under three FSW conditions are given in Figure 12. It is observed that both the average tensile strength and elongation of welded joints decreased under three FSW conditions. The tensile strength and elongation of the BM in the rolling direction are about $262.0 \mathrm{MPa}$ and $6.5 \%$, respectively. However, the tensile strength and elongation of the conventional FSW-produced joint are $218.8 \mathrm{MPa}$ and $3.6 \%$, which indicates approximately $16.5 \%$ and $44.6 \%$ reductions in the tensile strength and elongation.

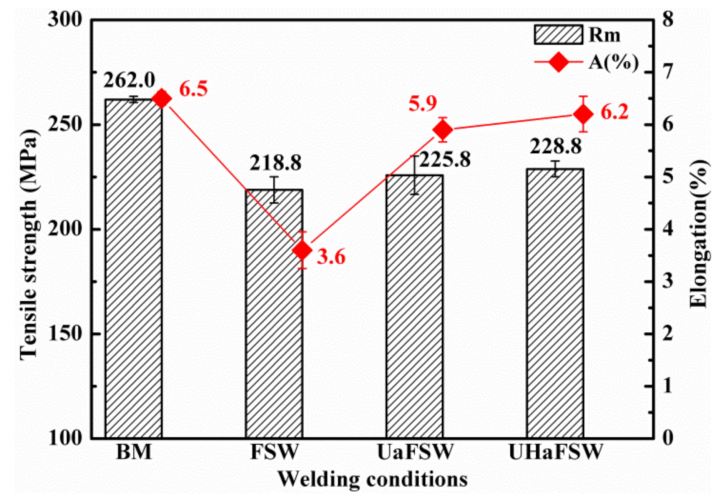

Figure 12. Comparison of the tensile properties of the AZ31 BM and the FSWed joints under three conditions (where $\mathrm{Rm}$ is the tensile strength and $\mathrm{A}$ is the elongation).

The average tensile strength of the welded joints under three FSW conditions are $218.8,225.8$, and $228.8 \mathrm{MPa}$, respectively. It means that the tensile strength of the UHaFSWproduced joint is approximately $4.6 \%$ and $1.3 \%$ higher than those of FSW-produced and UaFSW-produced joints, respectively. The tensile strength of UaFSW-produced joint is also about $3.2 \%$ higher than that of FSW-produced joint. Meanwhile, the trend in the elongation of the welded joints under three FSW conditions is consistent with the tensile strength as shown in Figure 12 (indicated by red broken line). Therefore, it is considered that the assistance of ultrasonic and heat pipe can significantly improve the tensile properties of welded joints during the FSW process.

The macroscopic fracture locations and surfaces of the BM and welded joints under three FSW conditions are shown in Figure 13. As seen from Figure 13a, it is found that all the fracture locations of the three FSWed joints are located at the TMAZ, but the fracture locations of the joints produced by UaFSW and UHaFSW are much closer to the NZ. Especially for the UHaFSW process, the fracture location is almost located at the interface between 
the NZ and the TMAZ. It means that the weakest location of FSW joint is transferred from the TMAZ to TMAZ-NZ due to the application of ultrasonic and heat pipe. The change may be due to two reasons: first, ultrasonic vibration improves the materials flow in the TMAZ; second, the decrease in the heat input leading to the grain coarsening is inhibited effectively in the TMAZ. The fracture angles of the three FSW tensile specimens are almost close to $45^{\circ}$, which indicates a typical shear fracture mode. Besides, it is worth noting that the fracture surface of the FSWed joint framed by the blue dotted line (Figure 13b) appears much darker and flatter than other regions, which probably implies the fracture source may be located in the darker and flatter region due to some potential cracks.

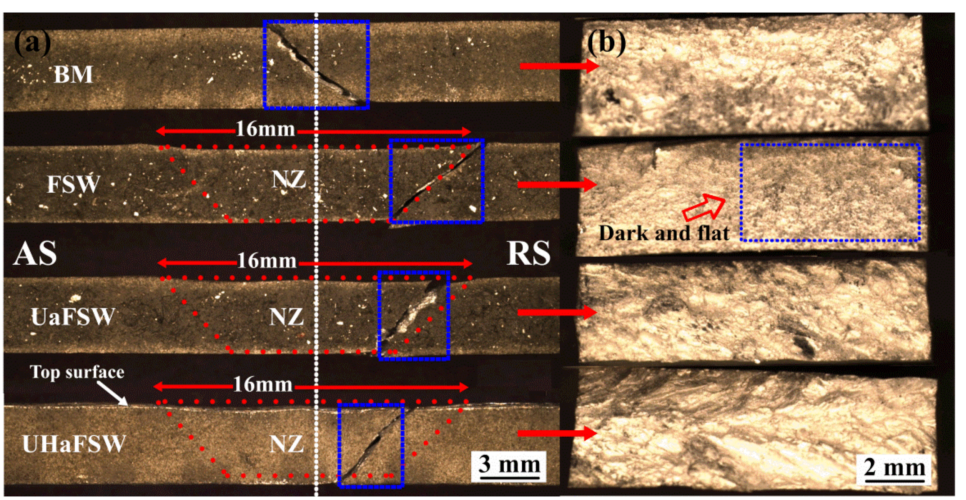

Figure 13. The macroscopic fracture morphologies of the BM and the tensile specimens chosen in the middle of the welded joints under three FSW conditions: (a) fracture locations, and (b) fracture surfaces.

Figure 14 shows typical SEM images of the tensile fracture surface of the BM and welded AZ31 Mg alloy joints under three FSW conditions. The fracture surface of the BM exhibits a typical cleavage fracture with few dimples, as shown in Figure 14a. As seen from Figure $14 b-d$, it is obvious that significant changes are presented in fractures. The tear ridges, cleavage facets in various sizes and a few of dimples could be observed under conventional FSW condition, which is considered as the typical brittle-ductile mixed fracture (Figure 14b). Compared with the conventional FSW condition, the welded joints produced UaFSW and UHaFSW by exhibit finer dimples on the fractured surfaces. The number of dimples obviously increase with a better uniform distribution, as shown in Figure $14 \mathrm{c}, \mathrm{d}$. Therefore, the fracture morphologies show the characteristics of microporous aggregate fracture, indicating the increase in the joints' strength. It is difficult to deform $\mathrm{Mg}$ and its alloys at room temperature because of the insufficient slip systems in close-packed hexagonal metallic materials except by heating or inputting extra energy to initiate the required slip systems for plastic deformation $[37,48,49]$. Under the UaFSW and UHaFSW conditions, the probable reduction in the deformation resistance of metal by ultrasonic vibration leads to the improvement in the material flow, which improves the backfill performance of materials flow from retreating side to advancing side. This phenomenon results in the better toughness of the welded joints. According to the Refs. [50,51], the quality of FSW-produced Mg alloys is highly related to the residual stress in the weld. During the FSW process, high-level tensile residual stresses can take place in the weld due to the restraint from base metal during weld cooling which causes the crack initiation and propagation, finally leading to a catastrophic failure. Due to the assistance of ultrasonic and heat pipe, the effective decrease in the peak temperature and the duration of high temperature leads to the grains' refinement in the nugget zone and probable reduction in a thermal expansion mismatch during cooling, which might reduce the residual stresses in weld and lead to the increase in the tensile strength and elongation of the welded joints. 


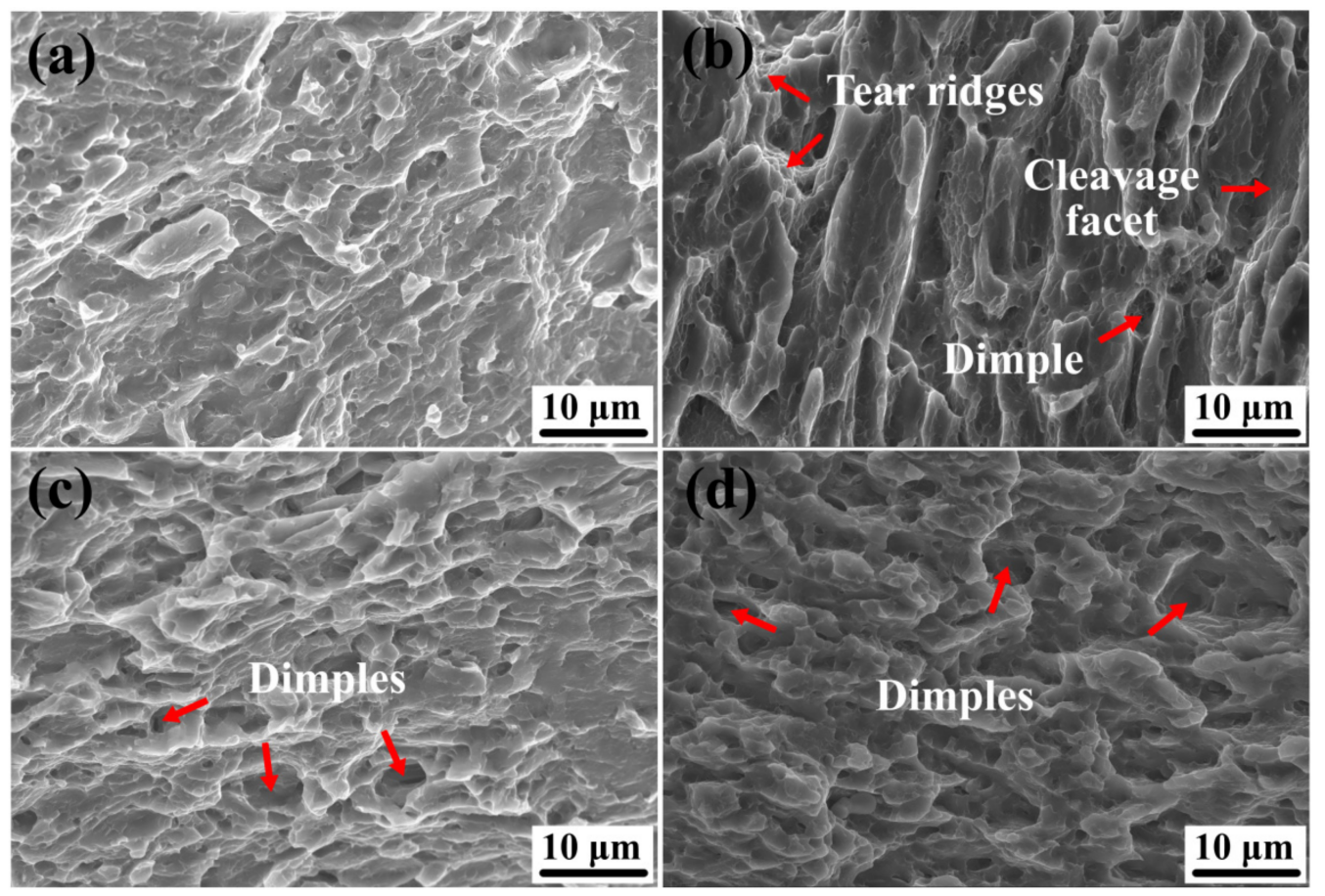

Figure 14. Typical SEM images of the tensile fracture surfaces of AZ31 Mg alloys under different conditions: (a) BM, (b) FSW, (c) UaFSW, and (d) UHaFSW.

\section{Conclusions}

In this work, the thermal cycle, welding temperature, microstructure, hardness, tensile properties, and fracture morphologies of AZ31 Mg alloys are investigated under three FSW conditions: conventional FSW (FSW), ultrasonic assisted FSW (UaFSW), and ultrasonic and heat pipe assisted FSW (UHaFSW). The main conclusions can be drawn as follows:

(1) During FSW process, the temperature distribution is non-uniform along the welding length and horizontal directions of the welded joint. A "dual peaks phenomenon" is presented at the initial stage of the FSW process, which can be obviously observed in the thermal cycle curve.

(2) Compared with conventional FSW, UHaFSW can effectively balance and improve the "nonuniformity" in the welding temperature field via the significant decrease in the peak temperature and average peaks temperature difference between corresponding AS and RS. Meanwhile, with the assistance of ultrasonic and heat pipe, UHaFSW significantly reduces the durations of high temperature, which inhibits the grain coarsening of the welded AZ31 Mg alloy joints during the process and leads to the refined equiaxial grains in the nugget zone.

(3) The cross-section profiles of welded joints under three FSW conditions are similar to a typical "shallow funnel" which is wider at the top and narrower at the bottom. The widest region of the whole nugget zone is presented under the UaFSW condition, followed by UHaFSW and conventional FSW conditions since the ultrasonic vibration leads to the materials softening and the promotion in the plastic deformation.

(4) Generally, compared with the base metal, the hardness across the whole welded joints declined after FSW, the hardness distribution profile presented a " $W$ " pattern, and the lowest hardness locations are presented between TMAZ and NZ. Compared with other FSW conditions, the overall average microhardness of the joint produced by UHaFSW increases by $5.2 \%$ and $2.5 \%$; the original " $\mathrm{W}$ " pattern of the hardness distribution profile is almost absent due to the homogeneous and refined microstructure.

(5) Compared with the conventional FSW, the average tensile strength and elongation of the welded joints significantly increase under the UaFSW and UHaFSW conditions. Correspondingly, the fractographies exhibit more and finer dimples on the fractured 
surfaces of the joints under the UaFSW and UHaFSW conditions. Likewise, the fracture morphologies show the characteristic of microporous aggregate fracture, which indicates the increase of joints strength under the UaFSW and UHaFSW conditions.

\begin{abstract}
Author Contributions: Conceptualization, C.-G.W., M.-Y.X. and S.L.; methodology, C.-G.W.; software, M.-Y.X.; validation, S.L. and C.-G.W.; formal analysis, C.-G.W. and M.-Y.X.; investigation, C.-G.W. and M.-Y.X.; resources, C.-G.W.; data curation, C.-G.W. and M.-Y.X.; writing-original draft preparation, C.-G.W.; writing-review and editing, L.-Y.C. and C.-G.W.; visualization, C.-G.W.; supervision, S.L.; project administration, S.L.; funding acquisition, S.L. All authors have read and agreed to the published version of the manuscript.
\end{abstract}

Funding: This research was funded by the National Natural Science Foundation of China (Grant Nos. 51375218 and 51675248), and the "Postgraduate Research \& Practice Innovation Program of Jiangsu Province" project (KYCX19_1664).

Data Availability Statement: The datasets presented in this article are not readily available because these findings cannot be shared at this time as the data also forms part of an ongoing study.

Acknowledgments: The authors would like to thank the support of the National Natural Science Foundation of China (Grant Nos. 51375218 and 51675248), and the "Postgraduate Research \& Practice Innovation Program of Jiangsu Province" project (KYCX19_1664).

Conflicts of Interest: The authors declare no conflict of interest. The funders had no role in the design of the study; in the collection, analyses, or interpretation of data; in the writing of the manuscript, or in the decision to publish the results.

\title{
References
}

1. Wayne, M.; Edward, D.; James, C.; Michael, G.; Peter, T.; Christopher, J.S. Friction welding. Weld. J. 1999, 78, 56. [CrossRef]

2. Nandan, R.; DebRoy, T.; Bhadeshia, H.K.D.H. Recent advances in friction-stir welding-Process, weldment structure and properties. Prog. Mater. Sci. 2008, 53, 980-1023. [CrossRef]

3. Singh, K.; Singh, G.; Singh, H. Review on friction stir welding of magnesium alloys. J. Magnes. Alloy. 2018, 6, 399-416. [CrossRef]

4. Eren, B.; Guvenc, M.A.; Mistikoglu, S. Artificial Intelligence Applications for Friction Stir Welding: A Review. Met. Mater. Int. 2021, 27, 193-219. [CrossRef]

5. Laska, A.; Szkodo, M. Manufacturing parameters, materials, and welds properties of butt friction stir welded joints-overview. Materials 2020, 13, 4940. [CrossRef]

6. Heidarzadeh, A.; Mironov, S.; Kaibyshev, R.; Çam, G.; Simar, A.; Gerlich, A.; Khodabakhshi, F.; Mostafaei, A.; Field, D.P.; Robson, J.D.; et al. Friction Stir Welding/Processing of Metals and Alloys: A Comprehensive Review on Microstructural Evolution. Prog. Mater. Sci. 2020, 117, 100752. [CrossRef]

7. Meng, X.; Huang, Y.; Cao, J.; Shen, J.; dos Santos, J.F. Recent progress on control strategies for inherent issues in friction stir welding. Prog. Mater. Sci. 2021, 115, 100706. [CrossRef]

8. He, X.; Gu, F.; Ball, A. A review of numerical analysis of friction stir welding. Prog. Mater. Sci. 2014, 65, 1-66. [CrossRef]

9. Wang, L.; Xie, L.; Lv, Y.; Zhang, L.C.; Chen, L.; Meng, Q.; Qu, J.; Zhang, D.; Lu, W. Microstructure evolution and superelastic behavior in Ti-35Nb-2Ta-3Zr alloy processed by friction stir processing. Acta Mater. 2017, 131, 499-510. [CrossRef]

10. Xu, N.; Zhang, W.; Cai, S.; Zhuo, Y.; Song, Q.; Bao, Y. Microstructure and tensile properties of rapid-cooling friction-stir-welded AZ31B Mg alloy along thickness direction. Trans. Nonferrous Met. Soc. China Engl. Ed. 2020, 30, 3254-3262. [CrossRef]

11. Mehta, K.P.; Carlone, P.; Astarita, A.; Scherillo, F.; Rubino, F.; Vora, P. Conventional and cooling assisted friction stir welding of AA6061 and AZ31B alloys. Mater. Sci. Eng. A 2019, 759, 252-261. [CrossRef]

12. Chowdhury, S.H.; Chen, D.L.; Bhole, S.D.; Cao, X.; Wanjara, P. Friction stir welded AZ31 magnesium alloy: Microstructure, texture, and tensile properties. Metall. Mater. Trans. A Phys. Metall. Mater. Sci. 2013, 44, 323-336. [CrossRef]

13. Silva-Magalhães, A.; De Backer, J.; Martin, J.; Bolmsjö, G. In-situ temperature measurement in friction stir welding of thick section aluminium alloys. J. Manuf. Process. 2019, 39, 12-17. [CrossRef]

14. Mironov, S.; Sato, Y.S.; Kokawa, H. Influence of welding temperature on material flow during friction stir welding of AZ31 magnesium alloy. Metall. Mater. Trans. A Phys. Metall. Mater. Sci. 2019, 50, 2798-2806. [CrossRef]

15. Bilgin, M.; Karabulut, Ş.; Özdemir, A. Investigation of Heat-Assisted Dissimilar Friction Stir Welding of AA7075-T6 Aluminum and AZ31B Magnesium Alloys. Arab. J. Sci. Eng. 2020, 45, 1081-1095. [CrossRef]

16. Padhy, G.K.; Wu, C.S.; Gao, S. Precursor ultrasonic effect on grain structure development of AA6061-T6 friction stir weld. Mater. Des. 2017, 116, 207-218. [CrossRef]

17. Liu, H.; Hu, Y.; Du, S.; Zhao, H. Microstructure characterization and mechanism of acoustoplastic effect in friction stir welding assisted by ultrasonic vibrations on the bottom surface of workpieces. J. Manuf. Process. 2019, 42, 159-166. [CrossRef] 
18. Zhang, Z.; He, C.; Li, Y.; Yu, L.; Zhao, S.; Zhao, X. Effects of ultrasonic assisted friction stir welding on flow behavior, microstructure and mechanical properties of 7N01-T4 aluminum alloy joints. J. Mater. Sci. Technol. 2020, 43, 1-13. [CrossRef]

19. Shi, L.; Wu, C.S.; Liu, X.C. Modeling the effects of ultrasonic vibration on friction stir welding. J. Mater. Process. Technol. 2015, 222, 91-102. [CrossRef]

20. Liu, Z.; Ji, S.; Meng, X. Joining of magnesium and aluminum alloys via ultrasonic assisted friction stir welding at low temperature. Int. J. Adv. Manuf. Technol. 2018, 97, 4127-4136. [CrossRef]

21. Zhong, Y.B.; Wu, C.S.; Padhy, G.K. Effect of ultrasonic vibration on welding load, temperature and material flow in friction stir welding. J. Mater. Process. Technol. 2017, 239, 273-283. [CrossRef]

22. Ma, Z.Y.; Feng, A.H.; Chen, D.L.; Shen, J. Recent Advances in Friction Stir Welding/Processing of Aluminum Alloys: Microstructural Evolution and Mechanical Properties. Crit. Rev. Solid State Mater. Sci. 2018, 43, 269-333. [CrossRef]

23. Reay, D.A.; Kew, P.A. 7-Applications of the Heat Pipe. In Heat Pipes, 5th ed.; Kew, P.A., Ed.; Butterworth-Heinemann: Oxford, UK, 2007; pp. 275-317. ISBN 9780750667548.

24. Zhang, H.; Zhuang, J. Research, development and industrial application of heat pipe technology in China. Appl. Therm. Eng. 2003, 23, 1067-1083. [CrossRef]

25. Bahmani, M.H.; Sheikhzadeh, G.; Zarringhalam, M.; Akbari, O.A.; Alrashed, A.A.A.A.; Shabani, G.A.S.; Goodarzi, M. Investigation of turbulent heat transfer and nanofluid flow in a double pipe heat exchanger. Adv. Powder Technol. 2018, 29, 273-282. [CrossRef]

26. Faghri, A.; Guo, Z. Integration of heat pipe into fuel cell technology. Heat Transf. Eng. 2008, 29, 232-238. [CrossRef]

27. Antariksawan, A.R.; Juarsa, M.; Sundari, T.; Ismarwanti, S.; Widodo, S.; Kusuma, M.H.; Subekti, M.; Putra, N. Study of heat transfer in a water cooling tank with c-shaped heat exchanger and straight heat pipe under natural circulation. AIP Conf. Proc. 2019, 2062, 020007. [CrossRef]

28. Lu, S.; Zhang, W.; Chen, S.; Yao, S. Effect of flat heat pipe on the properties of the FSW joint. Mater. Sci. Forum 2016, 850, 693-699. [CrossRef]

29. Zhang, Y.-M.; Chen, L.-Y.; Lu, S.; Zhao, C.; Wang, Y.-H. Refined Microstructure and Enhanced Hardness in Friction Stir-Welded AZ31 Magnesium Alloy Induced by Heat Pipe with Different Cooling Liquid. Metals 2019, 9, 1227. [CrossRef]

30. ASTM. ASTM E112-13: Standard test methods for determining average grain size. ASTM Int. 2013, 3, 1-28. [CrossRef]

31. Rubino, F.; Parmar, H.; Esperto, V.; Carlone, P. Ultrasonic welding of magnesium alloys: A review. Mater. Manuf. Process. 2020, 35 , 1051-1068. [CrossRef]

32. Sheng, L.; Jing, C.; Jia, X.D.; Wang, Z.X.; Gong, J.J. Thermal cycle characteristics of AM 50 magnesium alloy welded by FSW. Key Eng. Mater. 2010, 419-420, 533-536. [CrossRef]

33. Keivani, R.; Bagheri, B.; Sharifi, F.; Ketabchi, M.; Abbasi, M. Effects of pin angle and preheating on temperature distribution during friction stir welding operation. Trans. Nonferrous Met. Soc. China Engl. Ed. 2013, 23, 2708-2713. [CrossRef]

34. Cho, J.-H.; Boyce, D.E.; Dawson, P.R. Modeling strain hardening and texture evolution in friction stir welding of stainless steel. Mater. Sci. Eng. A 2005, 398, 146-163. [CrossRef]

35. Yan, F.; Zhang, Y.C.; Shen, J.; Fu, X.B.; Mi, S. A new calculation method of viscoplastic heat production generated by plastic flow of friction stir welding process. Mater. Chem. Phys. 2021, 270, 124795. [CrossRef]

36. Abbasi, M.; Bagheri, B.; Sharifi, F. Simulation and experimental study of dynamic recrystallization process during friction stir vibration welding of magnesium alloys. Trans. Nonferrous Met. Soc. China Engl. Ed. 2021, 31, 2626-2650. [CrossRef]

37. Su, C.W.; Lu, L.; Lai, M.O. Recrystallization and grain growth of deformed magnesium alloy. Philos. Mag. 2008, 88, 181-200. [CrossRef]

38. Ugender, S. Influence of tool pin profile and rotational speed on the formation of friction stir welding zone in AZ31 magnesium alloy. J. Magnes. Alloy. 2018, 6, 205-213. [CrossRef]

39. Naik, B.S.; Chen, D.L.; Cao, X.; Wanjara, P. Texture development in a friction stir lap-welded AZ31B magnesium alloy. Metall. Mater. Trans. A Phys. Metall. Mater. Sci. 2014, 45, 4333-4349. [CrossRef]

40. Zang, Q.; Chen, H.; Lan, F.; Zhang, J.; Jin, Y. Effect of friction stir processing on microstructure and damping capacity of AZ31 alloy. J. Cent. South Univ. 2017, 24, 1034-1039. [CrossRef]

41. Wlodarski, S.; Avery, D.Z.; White, B.C.; Mason, C.J.T.; Cleek, C.; Williams, M.B.; Allison, P.G.; Jordon, J.B. Evaluation of Grain Refinement and Mechanical Properties of Additive Friction Stir Layer Welding of AZ31 Magnesium Alloy. J. Mater. Eng. Perform. 2021, 30, 964-972. [CrossRef]

42. Commin, L.; Dumont, M.; Masse, J.E.; Barrallier, L. Friction stir welding of AZ31 magnesium alloy rolled sheets: Influence of processing parameters. Acta Mater. 2009, 57, 326-334. [CrossRef]

43. Han, G.; Lee, K.; Yoon, J.Y.; Na, T.W.; Ahn, K.; Kang, M.J.; Jun, T.S. Effect of post-weld heat treatment on mechanical properties of local weld-affected zones in friction stir welded AZ31 plates. Mater. Sci. Eng. A 2021, 805, 140809. [CrossRef]

44. Shang, Q.; Ni, D.R.; Xue, P.; Xiao, B.L.; Wang, K.S.; Ma, Z.Y. An approach to enhancement of Mg alloy joint performance by additional pass of friction stir processing. J. Mater. Process. Technol. 2019, 264, 336-345. [CrossRef]

45. Sahu, P.K.; Das, J.; Chen, G.; Liu, Q.; Pal, S.; Zeng, S.; Shi, Q. Friction stir selective alloying of different Al\% particulate reinforced to AZ31 Mg for enhanced mechanical and metallurgical properties. Mater. Sci. Eng. A 2020, 774, 138889. [CrossRef]

46. Han, Y.; Jiang, X.; Chen, S.; Yuan, T.; Zhang, H.; Bai, Y.; Xiang, Y.; Li, X. Microstructure and mechanical properties of electrically assisted friction stir welded AZ31B alloy joints. J. Manuf. Process. 2019, 43, 26-34. [CrossRef] 
47. Wang, G.; Yan, Z.; Zhang, H.; Zhang, X.; Liu, F.; Wang, X.; Su, Y. Improved properties of friction stir-welded AZ31 magnesium alloy by post-weld heat treatment. Mater. Sci. Technol. 2017, 33, 854-863. [CrossRef]

48. Zhang, J.; Chen, X.; Liu, S.; Huang, G.; Jiang, B.; Tang, A.; Pan, F. Non-uniform deformation behavior of dissimilar friction stir welded AM60/AZ31 joint and its influence on fracture. Mater. Sci. Eng. A 2021, 800, 140318. [CrossRef]

49. Cao, Y.; Ni, S.; Liao, X.; Song, M.; Zhu, Y. Structural evolutions of metallic materials processed by severe plastic deformation. Mater. Sci. Eng. R Rep. 2018, 133, 1-59. [CrossRef]

50. Commin, L.; Dumont, M.; Rotinat, R.; Pierron, F.; Masse, J.-E.; Barrallier, L. Influence of the microstructural changes and induced residual stresses on tensile properties of wrought magnesium alloy friction stir welds. Mater. Sci. Eng. A 2012, 551, $288-292$. [CrossRef]

51. Hou, Z.; Sheikh-Ahmad, J.; Jarrar, F.; Ozturk, F. Residual Stresses in Dissimilar Friction Stir Welding of AA2024 and AZ31: Experimental and Numerical Study. J. Manuf. Sci. Eng. Trans. ASME 2018, 5. [CrossRef] 